\title{
Itinerancia comercial y control social. Trayectorias de mercachifles árabes en la Patagonia septentrional, Argentina [1900-1935]
}

Resumen: En este artículo se reconstruyen experiencias de vendedores ambulantes sirio-libaneses en el sur de Río Negro y en el norte de Chubut, durante las primeras décadas del siglo XX. Se analizan en profundidad dos procesos policiales que permiten discutir las condiciones materiales y las estrategias de movilidad de los mercachifles árabes. Se argumenta que las fuerzas policiales intentaron regular y disciplinar el comercio itinerante, aunque los buhoneros sirio-libaneses tuvieron éxito al defender sus intereses y mantener circuitos mercantiles que podían escapar al control estatal.

Palabras clave: estudios migratorios, sirio-libaneses, venta ambulante, nomadismo, circulación.

\section{Commercial itinerance and social control. Trajectories of Arab hucksters in Northern Patago- nia, Argentina [1900-1935]}

Abstract: This article reconstructs the experiences of Syrian and Lebanese peddlers in the south of Río Negro and the north of Chubut during the first decades of the 20th century. Two police processes, which allow discussing the material conditions and mobility strategies of Arab merchants, are analyzed in depth. It argues that the police forces attempted to regulate and discipline itinerant trade. However, Syrian-Lebanese peddlers successfully defended their interests and maintained commercial circuits to escape state control.

Keywords: migration studies, Syrian-Lebanese, peddling, nomadism, circulation.

\section{Itinerância comercial e controle social. Trajetórias de vendedores ambulantes árabes no norte da Patagônia, Argentina [1900-1935]}

Resumo: Este artigo reconstrói as experiências de vendedores ambulantes sírios e libaneses no sul de Río Negro e no norte de Chubut, durante as primeiras décadas do século XX. São analisados em profundidade dois processos policiais que permitem discutir as condições materiais e as estratégias de mobilidade dos comerciantes árabes. Argumenta-se que as forças policiais tentaram regular e disciplinar o comércio itinerante, mas os mascates sírio-libaneses tiveram sucesso na defesa de seus interesses e na manutenção de circuitos comerciais que podiam escapar ao controle do Estado. Palavras-chave: estudos de migração, sírio-libaneses, comércio ambulante, nomadismo, circulação.

Cómo citar este artículo: Matías Chávez, "Itinerancia comercial y control social. Trayectorias de mercachifles árabes en la Patagonia septentrional, Argentina [1900-1935]”, Trashumante. Revista Americana de Historia Social 19 [2022]: 118-139.

DOI: 10.17533/udea.trahs.n19a06

Fecha de recepción: 16 de febrero de 2021

Fecha de aprobación: 22 de julio de 2021

Matías Chávez: Doctor en Historia por la Universidad Nacional del Centro de la Provincia de Buenos Aires.

Becario posdoctoral del Instituto Patagónico de Ciencias Sociales y Humanas [IPCSH-CONICET] y profesor de la Universidad Nacional de la Patagonia San Juan Bosco. ORCID: 0000-0002-2125-2990.

Correo electrónico: matiaschavez22@gmail.com 


\title{
Itinerancia comercial y control social. Trayectorias de mercachifles árabes en la Patagonia septentrional, Argentina [1900-1935]
}

\author{
Matías Chávez \\ Introducción
}

$\mathrm{L}$ os inmigrantes árabes practicaron la venta ambulante de mercaderías y el acopio de productos rurales en la Patagonia septentrional desde principios del siglo XX. Estos comerciantes fueron identificados genéricamente como mercachifles, un término muy difundido en distintos países de América que generalmente se emplea para referirse a "vendedores de poca monta" y que frecuentemente tiene connotaciones negativas. Si bien en el sur de Argentina operaron buhoneros de diferentes nacionalidades, suele asumirse que existe en la Patagonia un vínculo prácticamente indisociable entre el oficio de mercachifle y los inmigrantes siriolibaneses. ${ }^{1}$

Los estudios históricos y antropológicos han destacado la importancia económica y social de los mercachifles árabes en la Patagonia, al mismo tiempo que han contribuido a desmontar los estereotipos más arraigados sobre estos actores. Existe consenso en la literatura especializada — que se recupera más adelante en el apartado sobre los antecedentes - en que los buhoneros frecuentemente entablaron

* El artículo se basa parcialmente en un capítulo de la tesis doctoral del autor. Matías Chávez, "Cartografias árabes. Trayectorias, territorialidad y redes sociales de inmigrantes sirio-libaneses en la Patagonia septentrional (1900-1955)" (Tesis de doctorado en Historia, Universidad Nacional del Centro de la Provincia de Buenos Aires, 2019).

1. Susana Bandieri destacó la presencia de los vendedores ambulantes árabes en su síntesis sobre el panorama migratorio de Patagonia a comienzos del siglo XX: "Unos pocos migrantes de ultramar se asentaron en los valles fluviales donde se desarrollaban cultivos agrícolas, como es el caso de las poblaciones de origen galés en el territorio chubutense o de los españoles e italianos en el Alto Valle del río Negro, en tanto que los mercachifles - mercaderes ambulantes-, generalmente de nacionalidad sirio-libanesa, recorrían la meseta”. Susana Bandieri, Historia de la Patagonia (Buenos Aires: Sudamericana, 2005) 173. En el mismo sentido, recientemente Santiago Conti subrayó la sinonimia que existe entre mercachifle y "turco" en el imaginario colectivo de la región. Santiago Conti, "Mercachifle. (Región Patagonia, Argentina, 1900-2019)”, Diccionario del agro iberoamericano, eds. Alejandra Salomón y José Muzlera (Buenos Aires:TeseoPress, 2020) 390. 
con los productores rurales relaciones comerciales asimétricas, lo que derivó en situaciones de abuso por parte de los vendedores ambulantes. Pese a los importantes avances de las investigaciones sobre los mercachifles, existen dimensiones de sus experiencias que no han sido suficientemente estudiadas, como, por ejemplo, la relación entre los buhoneros árabes y los agentes estatales que estaban encargados de regular su actividad.

En este artículo se analizan las trayectorias de mercachifles sirio-libaneses y se reconstruyen sus condiciones materiales — sus mercancías, pertenencias y medios de movilidad - y el alcance espacial de sus redes de negocios, al mismo tiempo que se busca comprender sus estrategias de alta movilidad. Para ello, se abordan fuentes policiales y judiciales que ofrecen abundante información sobre actores que suelen tener baja visibilidad en otros archivos. Si bien este tipo de expedientes tienden a sobrerrepresentar el conflicto social, resultan sumamente útiles para rastrear las tensiones que se produjeron entre los buhoneros y las fuerzas policiales. En este sentido, se argumentará que la policía no solo fue la institución que ejerció el control sobre el comercio ambulante, sino que fue la encargada de disciplinar los nomadismos que podían escapar a la regulación estatal.

Esta investigación se concentra en las primeras décadas del siglo XX, periodo que puede considerarse como el del inicio y auge del comercio itinerante de los sirio-libaneses en la Patagonia, aunque muchos mercachifles árabes se mantuvieron activos en las décadas siguientes. ${ }^{2}$ En cuanto al recorte espacial, el mismo comprende el sur del Territorio Nacional de Río Negro y el norte del de Chubut, dos espacios con fuertes vinculaciones históricas y con un límite entre ambas jurisdicciones sumamente poroso (Figura 1).

De las distintas etapas del ciclo migratorio de los sirio-libaneses en la Patagonia, la fase del comercio itinerante es la más compleja de reconstruir, debido a la escasa disponibilidad de fuentes. Los principales documentos para abordar la venta ambulante árabe continúan siendo las memorias de los comerciantes, quienes evocan sus inicios como buhoneros, o los recuerdos de sus descendientes. Si bien esas historias orales pueden contribuir a la comprensión de estos procesos, suelen repasar someramente los inicios, y habitualmente se limitan a justificar la etapa posterior en que se establecieron los comercios fijos. Además, ese tipo de relatos tienden a privilegiar las trayectorias mercantiles más exitosas. Fue en una etapa avanzada de la investigación sobre las experiencias de los inmigrantes sirio-libaneses en la Patagonia cuando se logró articular un conjunto heterogéneo de fuentes que permitió discutir las prácticas itinerantes de los vendedores árabes. Hasta ese momento, había sido como si el archivo de los comerciantes sirio-libaneses se hubiese instituido recién en la etapa en que estos inmigrantes se establecieron con boliches, ${ }^{3}$ y se

2. Se estudia a los inmigrantes sirio-libaneses como un colectivo unificado, aunque ese rótulo aglutina a distintos subgrupos que arribaron desde el Cercano Oriente. Inicialmente, en el colectivo migratorio árabe convivieron distintas adscripciones, no obstante, rápidamente estos inmigrantes optaron por asociarse como sirio-libaneses, y así se reconocieron frente a otros.

3. El término "boliche" hace referencia a comercios rurales de escala intermedia. 
Figura 1. Región de estudio

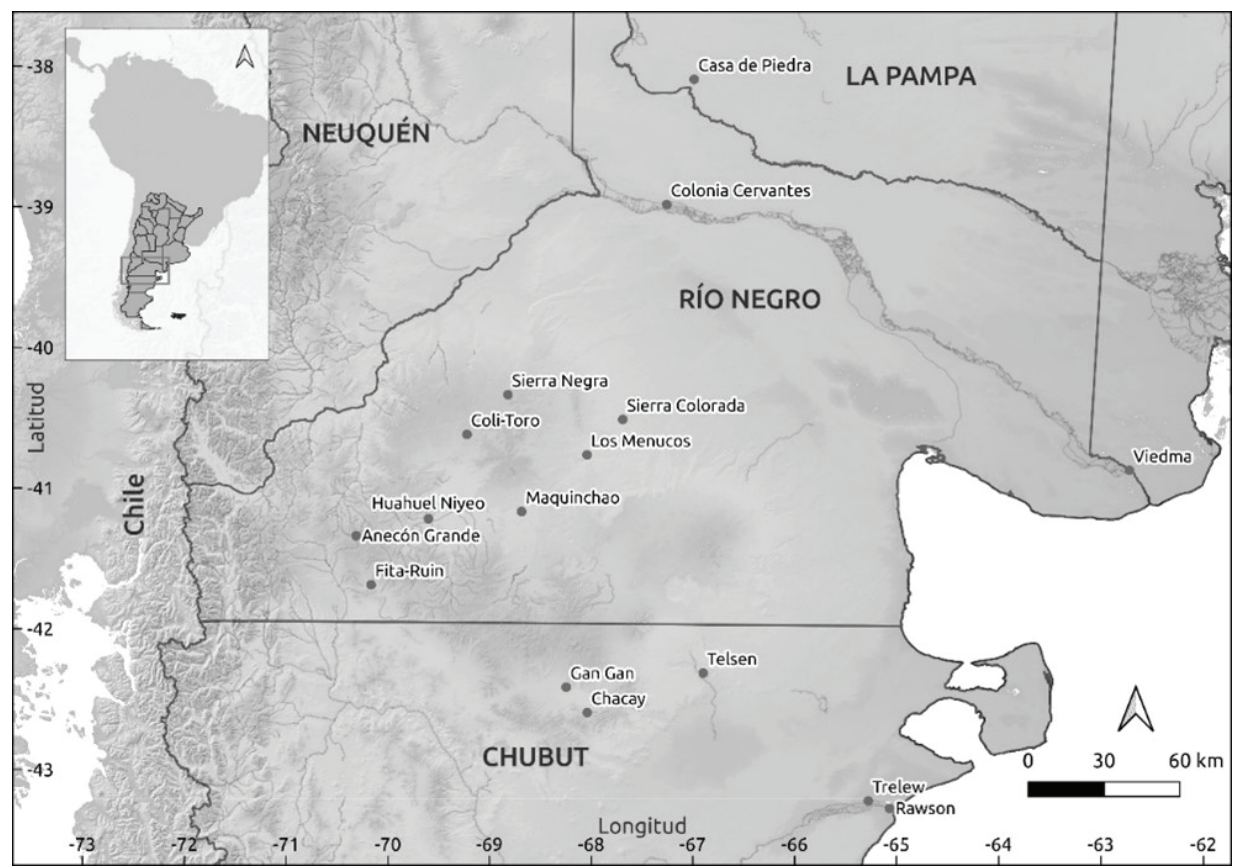

Fuente: Elaborado por Lucas Bandieri.

obliteraba así la necesaria fase ambulante previa. En algún sentido, parecía que las memorias sobre la etapa sedentaria y "civilizada" del boliche hubiese borrado la fase "primitiva" de los mercachifles.

Diferentes causas permiten explicar la limitada producción de evidencias de archivo sobre la venta ambulante. Como se verá más adelante, los mercachifles debían cumplir pocos requisitos legales y administrativos para obtener patentes comerciales y no estaban obligados a registrar sus operaciones de ventas. Es posiblemente por ello que las huellas documentales más sólidas sobre sus prácticas itinerantes surgen de expedientes policiales y judiciales.

Para reconstruir las trayectorias de los mercachifles árabes se utilizaron, además de los ya mencionados documentos judiciales y policiales, expedientes de las gobernaciones de Río Negro y Chubut, inspecciones de la Dirección General de Tierras, estadísticas oficiales y fragmentos de prensa. La estrategia de investigación se fundamenta en el estudio de casos y sigue la propuesta de Nélida Archenti para presentar un estudio denso y narrado en toda su diversidad, a fin de desentrañar sentidos generales a partir de casos individuales. ${ }^{4}$ Si bien la investigación se basa

4. Nélida Archenti, "Estudio de caso/s", Metodología de las ciencias sociales, eds. Alberto Marradi, Nélida Archenti y Juan Ignacio Piovani (Buenos Aires: Emecé Editores, 2007) 237-246. 
en lo fundamental en fuentes documentales, las entrevistas con descendientes de comerciantes ambulantes árabes ayudaron a comprender las particularidades de ese oficio. En este sentido, las conversaciones con Antonio Seleme, un experimentado mercachifle de ascendencia árabe, fueron sumamente útiles para entender las lógicas itinerantes. ${ }^{5}$

A continuación, se recuperan algunos de los principales antecedentes de investigaciones sobre los vendedores ambulantes árabes en Patagonia y se contextualiza la actividad de los buhoneros, para luego avanzar en el análisis de procedimientos policiales y judiciales protagonizados por mercachifles sirio-libaneses.

\section{Antecedentes y contexto histórico}

Existen estudios significativos sobre mercachifles en la Patagonia septentrional y regiones cercanas, aunque son pocas las investigaciones que se pueden verificar sobre los vendedores ambulantes árabes en particular. Desde la antropología rural, Juan Carlos Radovich y Alejandro Omar Balazote analizaron el intercambio comercial de la reserva mapuche de Pilcaniyeu, en el oeste de la provincia de Río Negro, durante la década de 1980, y señalan que los dos intermediarios más frecuentes en sus operaciones comerciales eran los mercachifles y la cooperativa Amulein Com. ${ }^{6}$ En ese trabajo se indica que desde inicios del siglo XX, los pobladores indígenas y los vendedores ambulantes establecieron vínculos complejos que no pueden reducirse a la mera exacción de excedente por parte de los mercachifles. Los autores argumentan que, si bien se trató de relaciones económicas asimétricas en favor de los vendedores ambulantes, en muchos casos el vínculo fue de reciprocidad e implicó lazos sociales que superaban la relación estrictamente económica.

Marta Madariaga estudió el intercambio mediante trueque entre productores rurales y mercachifles en la localidad de Comallo, en la línea sur de Río Negro, y señala que eran los pequeños comerciantes quienes hacían posible la venta de productos primarios, ${ }^{7}$ al mismo tiempo que los buhoneros posibilitaban el acceso a bienes de consumo y dinero por parte de los productores. La autora también explica que, si bien los vendedores ambulantes podían representar muchas veces el único medio viable de comercialización, frecuentemente propiciaban una dependencia comercial y generaban situaciones de abuso.

5. Antonio Seleme es un comerciante que actualmente radica en Puerto Madryn y que trabajó muchos años como mercachifle, inicialmente junto con su padre libanés y luego por cuenta propia. Seleme se desempeñó como vendedor ambulante en la meseta norte de Chubut y en Península Valdés entre las décadas de 1940 y 1960.

6. Juan Carlos Radovich y Alejandro Omar Balazote, "Mercachifles y cooperativas: un análisis del intercambio", Runa. Archivo para las Ciencias del Hombre 19 (1989-1990): 135-146.

7. Marta Madariaga, "El trueque en los sistemas agrarios campesinos", Crianceros y chacareros en la Patagonia, coords. Mónica Bendini y Carlos Alemany (Neuquén: Editorial La Colmena, 2004) 77-90. 
Por su parte, María Eugenia Comerci mostró la pervivencia de relaciones comerciales desiguales entre productores rurales y mercachifles desde principios del siglo XX en el oeste de La Pampa. ${ }^{8}$ La autora enfatizó la continuidad de vínculos comerciales asimétricos signados por la escasa capacidad de negociación de los campesinos y por el monopsonio que impusieron los vendedores ambulantes. No obstante, Comerci señala que la aparición durante los últimos años de nuevos demandantes para los productos primarios, la mejora de las vías de comunicación y el mayor acceso de los puesteros a camionetas han reducido la dependencia respecto de los mercachifles. La autora argumenta que estos intercambios se han mantenido, más allá de las desigualdades, porque se trata de vínculos históricos sostenidos fuertemente por la costumbre. Los trabajos mencionados comparten conclusiones que destacan las marcadas asimetrías comerciales entre las partes, al mismo tiempo que reconocen una larga continuidad en las relaciones sociales atravesadas por aspectos extraeconómicos que contribuyen a que se mantengan vigentes.

Desde la historiografia regional, se ha considerado a los mercachifles como actores influyentes del interior patagónico, especialmente durante la primera mitad del siglo XX. Liliana E. Pérez destaca la importancia económica de los vendedores ambulantes en la meseta norte de Chubut, y señala que la mayoría de ellos fueron inmigrantes sirios y libaneses. ${ }^{9}$ A partir de entrevistas, la autora muestra que existieron redes familiares que sostenían los negocios de los buhoneros árabes. Por otra parte, Ana María Troncoso también incorpora a los mercachifles en su análisis sobre la meseta norte de Chubut, y argumenta que los productores rurales no dependieron exclusivamente de los vendedores ambulantes, ya que muchos de los pobladores realizaban viajes comerciales esporádicos a las principales ciudades de la región. ${ }^{10}$ No obstante, la autora subraya el peso económico y social de los mercachifles árabes en la zona, para luego destacar que estos operaban fundamentalmente a través de créditos que podían generar fuertes endeudamientos por parte de los productores rurales.

En la historiografia patagónica existe consenso en que los comerciantes árabes generalmente pasaban de una primera inserción como vendedores ambulantes a su establecimiento posterior como bolicheros. Esa transición necesariamente implicó transformaciones en los modos de ocupar y producir el espacio. Para comprender las diferencias entre el comercio itinerante y el mayormente fijo de los boliches, puede ser útil retomar la distinción entre espacios lisos y espacios estriados que proponen Gilles Deleuze y Félix Guattari. Estos autores postulan una diferencia conceptual entre los espacios lisos (vectoriales, proyectivos o topológicos) y los

8. María Eugenia Comerci, "Relaciones de intercambio en el oeste pampeano: el papel de los ambulantes”, Estudios Socioterritoriales. Revista de Geografía 18 (2015): 13-29.

9. Liliana E. Pérez, Tels'en. Una historia social de la meseta norte del Chubut. Patagonia 1890-1940 (Rawson: Secretaría de Cultura de Chubut, 2012) 101-129.

10. Ana María Troncoso, Todavía no: el proyecto civilizador entre las prácticas sociales y las estrategias de resistencia, de negociación y de apropiación en la meseta norte chubutense (1900-1970) (Trelew: [s.e.], 2015) 323-342. 
espacios estriados (métricos), al sostener que: "en un caso 'se ocupa el espacio sin medirlo', en el otro 'se mide para ocuparlo"”. ${ }^{11}$ En el primer caso, no hay rutas o jerarquías de caminos que hayan sido impuestas por un soberano. En este sentido, el espacio liso es el de los cuerpos nómades que los Estados históricamente han combatido o han intentado regular. ${ }^{12}$ En el segundo caso, el espacio está regulado y el tránsito se limita en el marco de un contexto eminentemente estatal, con un poder soberano que regula la circulación de bienes y personas, determina y jerarquiza las rutas, divide el territorio mediante un catastro e impone técnicas que buscan garantizar la separación jurídica entre los espacios públicos y privados. La fase ambulante del comercio de los inmigrantes sirio-libaneses parece ajustarse mejor a la lógica de un espacio mayormente liso, en un contexto en que estos actores podían eludir el control estatal, como se verá a continuación. Por otra parte, la etapa de afianzamiento del comercio fijo de los bolicheros árabes fue concomitante a la consolidación del Estado argentino en la región y se adecuó mejor a las nuevas formas de regular espacios estriados.

Los mercachifles árabes se insertaron en Patagonia sobre antiguas rastrilladas indígenas, mostrando su capacidad para escapar a la nueva vialidad que el Estado comenzaba a imponer, inmediatamente después de las campañas militares de la denominada Conquista del Desierto. Un ejemplo elocuente sobre las posibilidades de los mercachifles árabes de eludir los caminos normalizados se puede encontrar en las primeras etapas de la investigación policial por supuestas prácticas de antropofagia ritual en El Cuy. ${ }^{13}$ Durante ese proceso, el poblador Temu Muñoz declaró que una pareja de mercachifles árabes había pasado la noche en su casa, ubicada en Sierra Negra, y que luego habían seguido su viaje "cortando campo" con dirección a Maquinchao. ${ }^{14} \mathrm{Si}$ bien el comentario se enmarcó en un proceso policial que estuvo viciado de nulidad, debe considerarse que las declaraciones de los testigos solían tener una base verosímil, o por lo menos hacían referencia a prácticas habituales. En este sentido, el testimonio de Muñoz parece confirmar lo que otros relatos insinúan: los mercachifles árabes no se limitaban a la vialidad estatal en proceso de consolidación, sino que avanzaban siguiendo trayectorias no normalizadas.

11. Gilles Deleuze y Félix Guattari, Mil Mesetas. Capitalismo y esquizofrenia (Valencia: Pre-Textos, 1988) 488.

12. Deleuze y Guattari 374.

13. En ese proceso policial se acusó a un grupo de indígenas por el supuesto asesinato y consumo antropofágico de mercachifles sirio-libaneses, hechos que se habrían producido durante la primera década del siglo XX en zonas próximas a los parajes Lagunitas y Sierra Negra, en el sudoeste de Río Negro. Si bien existe abundante literatura sobre el caso, las reconstrucciones más rigurosas señalan que se trató de un proceso montado por agentes policiales que exageraron los sucesos. Asimismo, es posible que las actuaciones policiales hayan sido funcionales a los intereses de casas mercantiles que se disputaban el control de rutas y nodos comerciales en la región. María Elba Argeri, De guerreros a delincuentes. La desarticulación de las jefaturas indígenas y el poder judicial. Norpatagonia, 1880-1930 (Madrid: Consejo Superior de Investigaciones Científicas, 2005) 191-195.

14. AHPRN,Viedma, Sección Justicia Letrada, expediente 1875, t. I, f. 18. 
Pese a que el Estado argentino había logrado penetrar militarmente en la $\mathrm{Pa}$ tagonia desde fines del siglo XIX, en algunos espacios interiores su soberanía era mayormente enunciativa. Las agencias estatales se mostraban incapaces de ejercer control social sobre la circulación de personas, ganados y mercancías, en un escenario social caracterizado por la alta movilidad de la población y por la ausencia de límites efectivos entre las ocupaciones privadas y las jurisdicciones públicas. Esto no supone que los mercachifles sirio-libaneses se desplazaran en un "vacío" y que sus trayectorias no tuvieran sentido, sino que ellos seguían itinerarios particulares para conectar nichos comerciales. Al mismo tiempo, pensar el comercio ambulante árabe en vinculación con formas de nomadismo obliga a eludir lecturas que puedan estar fundadas en estereotipos y que exalten supuestas condiciones pioneras o románticas.

Se debe considerar que durante la primera mitad del siglo XX las prácticas vinculadas al nomadismo tuvieron una valoración mayormente negativa en la $\mathrm{Pa}$ tagonia. En distintos contextos, los pobladores buscaron desmarcarse del calificativo "nómade", pese a la alta movilidad que se registraba entre comerciantes y ganaderos. Por ejemplo, referentes indígenas como Miguel Nancuche Nahuelquir evitaban ser clasificados como "nómades" y endilgaban esas prácticas a los mercachifles extranjeros: "En sus demandas [las de Nahuelquir] la vida seminómada era atribuida a la que llevaban adelante los comerciantes ambulantes, mientras que la comunidad de Cushamen era la que practicaba la agricultura y había levantado los edificios de la escuela oficial". ${ }^{15}$ De ese modo, el líder indígena resignificaba con originalidad los estigmas que recaían sobre ellos y argumentaba que si para los discursos civilizatorios el nomadismo era sinónimo de barbarie, los bárbaros eran los buhoneros extranjeros.

También el rótulo "mercachifle" tuvo una carga peyorativa durante el periodo de estudio, lo cual quedó reflejado en los medios nacionales de prensa. El semanario Caras y Caretas publicó un artículo específico sobre los inmigrantes árabes en Buenos Aires durante los primeros años del siglo XX, allí se refería al nicho laboral de este grupo migratorio como el "ingrato oficio de mercachifles". ${ }^{16}$ En este sentido, es posible que la valoración social negativa de la venta ambulante — visión vinculada con discursos que criticaban la pobreza material de los mercachifles y consideraban que el comercio itinerante era perjudicial para los negocios fijoshaya contribuido a obliterar esa etapa inicial en las memorias de los inmigrantes árabes y sus descendientes.

Como se adelantó en la introducción, el principal obstáculo para reconstruir las experiencias de los mercachifles sirio-libaneses fue la escasa documentación disponible. En términos formales, la venta ambulante estaba regulada por el Código Rural, aunque allí solo existían seis artículos con disposiciones que alcanzaban únicamente a los acopiadores. En ellos se establecía que los mercachifles que

15. Ana Margarita Ramos, "Trayectorias de aboriginalidad en las comunidades mapuche del Noroeste de Chubut (1990-2003)" (Tesis de doctorado en Antropología, Universidad de Buenos Aires, 2005) 62.

16. "Los turcos en Buenos Aires", Caras y Caretas (Buenos Aires) 1 de marzo de 1902: 33. 
acopiaban productos rurales debían consignar la información sobre los objetos que compraban en un libro de registros, donde además tenían la obligación de detallar el nombre y el domicilio del vendedor. Cada libro comercial debía estar a disposición de las autoridades judiciales o policiales y de los hacendados que tuviesen sospechas sobre los acopiadores. ${ }^{17}$

Los sirio-libaneses que se insertaban económicamente como mercachifles debían cumplir pocos requisitos administrativos. En primer lugar, necesitaban tramitar una patente comercial anual que se obtenía mediante el pago de una módica suma de dinero a la subcolecturía de cada gobernación. ${ }^{18}$ Los permisos habilitaban a los buhoneros a operar en un solo departamento, ${ }^{19}$ aunque frecuentemente los comerciantes ambulantes incursionaban en otras jurisdicciones. El principal requisito para ser habilitado como mercachifle era no tener antecedentes policiales. Los encargados de producir los informes sobre "antecedentes y moralidad" eran los empleados de la policía, quienes eventualmente podían condicionar el acceso a los permisos. No obstante, las indagaciones policiales eran limitadas y muchas veces ineficientes. En algunos casos, las averiguaciones sobre los antecedentes de los inmigrantes sirio-libaneses eran difíciles por la flexibilidad del régimen onomástico que manejaban las agencias del Estado. Por ejemplo, cuando en 1927 el inmigrante árabe Meljem García solicitó una patente para comerciar como ambulante en la jurisdicción de Gan Gan, en el norte de Chubut, la jefatura de policía informó que en la etapa de averiguación de antecedentes no se habían encontrado registros sobre "Miguel García". ${ }^{20}$ En este caso, el error de comunicación respecto del nombre imposibilitó que se accediera a información útil.

Las patentes para el comercio ambulante eran personales e intransferibles, y si eventualmente se constataba que el permiso estaba en poder de un tercero, este era revocado. Eso le sucedió al mercachifle árabe Salim Gabra, quien en mayo de 1935 solicitó a la gobernación de Chubut, a través de la policía de Gan Gan, la rubricación y habilitación de un libro de acopio de frutos del país para trabajar en el departamento Telsen. ${ }^{21}$ El pedido fue denegado porque la patente de "vendedor y acopiador de frutos ambulante" en poder de Gabra había sido emitida originalmente en favor de José Saipe. Pese a que Gabra alegó que le había comprado el permiso a Saipe por el valor de 100 pesos, las autoridades territorianas decidieron inhabilitar su patente. Nótese que el mercachifle árabe había comerciado sin restricciones hasta que solicitó el libro de acopio, es decir, que la irregularidad no había sido detectada previamente por los controles estatales.

17. Código rural para los territorios nacionales sancionado por el honorable Congreso Nacional el 14 de agosto de 1894 (Buenos Aires: Imprenta y Encuadernación Latina, 1894) 21-22.

18. Las patentes comerciales para establecimientos mercantiles fijos y para vendedores ambulantes tenían validez por el año en curso.

19. En Argentina los departamentos son las divisiones territoriales de segundo orden.

20. AHPC, Rawson, Fondo Gobernación del Chubut, exp. 4713.

21. AHPC, Rawson, Fondo Gobernación del Chubut, exp. 2659. 
La policía era la institución encargada de fiscalizar las actividades de los mercachifles. En primer lugar, debían constatar que los buhoneros tuviesen una patente comercial vigente y que esta los habilitara para los rubros que efectivamente explotaban. Asimismo, tenían la obligación de reprimir la venta de bebidas alcohólicas, aunque había algunos comerciantes ambulantes que contaban con permisos para ese rubro. ${ }^{22}$ Finalmente, debían regular que los acopiadores no adquiriesen productos ilegales, como podían ser los cueros de animales cazados sin permiso. Aunque en este último punto podía existir cierta tolerancia por parte de los empleados policiales. ${ }^{23}$ Además de cumplir con las demandas administrativas, los mercachifles debían contar con un pequeño capital inicial para adquirir mercaderías y poder acceder a algún medio para transportar sus mercancías. La evolución técnica de la movilidad de los mercachifles pasó de la venta a pie, valiéndose de pequeños cajones, al empleo de caballos o mulas como animales de carga. Luego utilizaron carros con tracción animal, y, finalmente, autos y pequeños camiones. Aunque este no fue un proceso necesariamente lineal.

Los buhoneros sirio-libaneses generalmente se insertaban comercialmente a partir del adelanto de mercaderías de un familiar o un connacional previamente establecido. En esos casos, los inmigrantes no necesitaban un capital inicial y solían aprovechar esa casa de negocios como residencia temporal. Idealmente, luego de cuatro o cinco años, un mercachifle podía acumular capital suficiente para independizarse como bolichero. Algunos buhoneros árabes establecieron boliches durante un tiempo y luego volvieron a la actividad ambulante, mientras que otros se mantuvieron como mercachifles a lo largo del tiempo, sin que ello implicase un fracaso comercial.

Los vendedores ambulantes sirio-libaneses fueron acompañados en sus primeras incursiones al interior patagónico por baqueanos indígenas y criollos que les ayudaron a reconocer el territorio. ${ }^{24}$ Esos primeros viajes también fueron importantes

22. Según los registros estadísticos oficiales de 1926, en Chubut había 10 mercachifles árabes que contaban con permiso para la venta de "vinos y cervezas". AHPC, Rawson, Fondo Gobernación del Chubut, exp. 3346.

23. El sargento retirado Domingo Tello recordaba que en 1929 asumió funciones como responsable del destacamento de policía de El Caín, en el sur de Río Negro, sobre la meseta del Somuncurá. Tello relevó en el cargo a un agente de apellido Luján, quien, según denunciaron comerciantes de la región, había decomisado un gran número de cueros a "chulenguiadores" (cazadores de guanacos): "Entonces los chulenguiadores le avisaron a los turcos [Abid Ziede y Lametala] lo que pasaba con la policía [...] Iba con orden del comisario, dice, pero eran mentiras, no eran orden del comisario, eran orden de él nomás, pero en esa forma procedía. Entonces la gente se encontraba —imagínese - ..., asusta a los chulenguiadores, porque si agarraban veinte chulengos le quitaban diez... Se quejaron; entonces fui yo y me hice cargo de ese destacamento, y anduve investigando a ver si Luján se encontraba por ahí”. Rodolfo Casamiquela, Relatos policiales patagónicos del Sargento Tello (Trelew: Fundación Ameghino, 2006) 63. El relato muestra que existía cierta tolerancia policial respecto de la economía de subsistencia de los "chulenguiadores", fundamentalmente a partir de la presión que podían ejercer los comerciantes árabes.

24. Graciela Iuorno, Glenda Miralles y Karim Nasser apuntaron casos de mercachifles árabes que emplearon baqueanos indígenas en Río Negro: "desde 1904 a 1909, muchos árabes 
porque permitieron que los buhoneros identificaran lugares con potencialidades económicas para establecerse posteriormente.

Los comerciantes árabes mostraron una fuerte movilidad aun durante la etapa en que se establecieron con boliches. El comercio "fijo" solía complementarse con viajes estacionales en los que se acercaban hasta las viviendas de los pobladores para comprar o vender. Este tipo de intercambio era más conveniente para los bolicheros porque obtenían la lana y los frutos del país a menor precio, valores que son conocidos en la línea sur de Río Negro como "precios de tranquera" o "intercambio a tranquera". ${ }^{25} \mathrm{Si}$ bien los productores podían beneficiarse de la reducción de los costos de flete, el negocio siempre era más conveniente para los comerciantes, más aún porque esos intercambios se realizaban frecuentemente mediante trueque. El intercambio sin dinero resultaba más provechoso para los comerciantes porque tenían doble margen de beneficio, ya que el vendedor obtenía una primera ganancia por el precio agregado al costo de la mercadería y una segunda utilidad por la diferencia monetaria que obtenía cuando liquidaba los productos adquiridos.

La venta ambulante no fue para los sirio-libaneses una actividad necesariamente individual, pues ellos solían realizar sus viajes comerciales en pareja o en grupo. Esto no solo obedecía a razones de seguridad, sino que era una forma de iniciar en el oficio a los recién llegados, quienes se empleaban como peones de los mercachifles más experimentados. Asimismo, existe evidencia documental de que algunos buhoneros trabajaban en sociedad, posiblemente como una estrategia para reducir los riesgos económicos. ${ }^{26} \mathrm{Si}$ bien los vendedores ambulantes árabes podían aparecer como actores aislados y disgregados, en realidad estaban estrechamente vinculados entre sí y compartían espacios de sociabilidad con sus connacionales. En el siguiente apartado se repasa un expediente judicial que refleja ese tipo de dinámica.

\section{Condiciones materiales y movilidad de los mercachifles árabes}

El 19 de noviembre de 1921, el mercachifle José Salomón fue asesinado por el bolichero Adib Sede — ambos árabes — en Maquinchao, una localidad ubicada

— mercachifles recién llegados - comenzaron a viajar desde Gral. Roca hacia el sur del territorio con caballos, vagonetas o sulkys cargados con mercaderías, acompañados por algún peón nativo que oficiaba de baqueano y regresaban con productos locales: Eldahuk Hnos, Medhi y David y Miguel Yunes, entre otros, eran las firmas comerciales radicadas, para la época en General Roca”. Graciela Iuorno, Glenda Miralles y Karim Nasser, "Actores y espacio público en la etapa territorial rionegrina. El Departamento General Roca y su integración desigual”, Horizontes en perspectiva. Contribuciones para la Historia de Río Negro 1884-1955, coords. Martha Ruffini y Ricardo Freddy Masera (Viedma: Fundación Ameghino, 2007) 6-7.

25. Madariaga 84.

26. Jorge Gabriel trabajó como vendedor ambulante en sociedad con su connacional Antonio Fermín Sad, según consta en una causa judicial que inició el comerciante Elías Jalil contra el mencionado Sad por lesiones. "Sad Fermín Antonio y Jalil Juan Elías por lesiones",Viedma, 4 de octubre de 1915. AHPRN,Viedma, Sección Justicia Letrada, exp. 495. 
en el sudoeste de Río Negro. ${ }^{27}$ El hecho se produjo durante una reunión entre comerciantes sirio-libaneses en la cocina de una vivienda que lindaba con la casa comercial de los hermanos Juan y Julián Zgaib. Las actuaciones judiciales posteriores determinaron que ese día, por la mañana, seis comerciantes árabes se habían reunido para compartir un almuerzo. Los presentes eran: Felipe Abraham, José Adaime, Abdo Zgaib, Antonio Seleme, y los ya mencionados Sede y Salomón. Al parecer, el conflicto se suscitó a partir de una discusión entre Antonio Seleme y José Salomón por unos cueros de animales. Según los testigos, Sede intentó mediar en la disputa verbal y Salomón lo amenazó con una pistola. Rápidamente, los presentes lograron arrebatarle el arma; en ese momento, Salomón se dirigió a su carro de mercachifle y tomó un cuchillo con el que atacó a Sede. En el intento por defenderse de la afrenta, Sede corrió hasta el interior del comercio de los hermanos Zgaib y allí repelió la agresión con dos disparos de arma de fuego que produjeron la muerte de Salomón. Según los testimonios relevados en la causa, era frecuente que los comerciantes árabes se reuniesen en la casa de los hermanos Zgaib, por fuera del boliche. Los presentes declararon que los concurrentes se conocían y que algunos de ellos habían sido socios o habían realizado negocios entre sí. Asimismo, coincidieron en que Sede y Salomón eran amigos, que nunca se habían peleado y que no estaban ebrios al momento de los hechos.

Algunos de los comerciantes árabes que estuvieron en la reunión habían llegado a Maquinchao desde parajes lejanos. Antonio Seleme, por ejemplo, era bolichero en el paraje Coli-Toro y también socio de Adib Sede. ${ }^{28}$ Por su parte, Felipe Abraham tenía un comercio en Sierra Colorada. En tanto que José Salomón, aunque era mercachifle, anteriormente había explotado un boliche en Los Menucos en sociedad con su connacional, Norah Sad.

El juicio contra Adib Sede comenzó el 13 de diciembre de 1921, enViedma. El proceso fue breve; Sede argumentó que había actuado en legítima defensa y tanto el fiscal como el juez acordaron rápidamente sobreseerlo de forma definitiva. Pese a la brevedad del juicio, el expediente ofrece información sumamente interesante, como, por ejemplo, un inventario detallado de las pertenencias y las mercancías que transportaba el mercachifle Salomón al momento del homicidio. Por la originalidad del registro, a continuación, se reproduce la lista en extenso:

Un baúl conteniendo lo siguiente, un calzoncillo, tres pares zapatillas chicas, cuatro docena medias niño, tres tiradores, treinta y cuatro vainas chicas, dos frascos agua olor, cuarenta librito papel fumar, once ovillos de hilo tejer, veinte cajas de botones, doce madeja cinta hilera, diez carreteles de hilo, una docena lápiz, un acentador, tres cadenas para reloj, una gorra, ocho pañuelo de mano

27. "Adib A. Sede, homicidio", Viedma, 19 de noviembre de 1921. AHPRN, Viedma, Sección Justicia Letrada, exp. 1454.

28. Adib o Amado Sede formaba parte de la sociedad comercial "Elías y Adib Sede y Cía." junto con Elías Sede, José Salím Sede y José Antonio Sede (todos los mencionados de origen árabe), según consta en una de las inspecciones de tierras de Maquinchao. 1919-1920.AHPRN,Viedma, Sección Inspecciones Generales de Tierras, Pueblo de Maquinchao, f. 19. 
luto, una toalla, dos echarpe, una antiparra, cuatro luto para sombrero, cinco pares aros, un anillo, veinticuatro boquillas, un par gemelo, veintinueve horquillones surtidos, una docena tetas goma, tres espejos grandes, diez espejos bolsillos, tres pañuelos para cuello diferente, una boa, un baúl conteniendo ropa usada del extinto Salomón, y un cajoncito conteniendo cinco matras usadas, un carpincho usado, un par bastos, una lona vieja y un tirador, seis libretas, cinco recibos varios, nueve certificados y un legajo cuentas varias. Cuatro caballos siguientes marcas y pelos [...] y un carro de dos ruedas de varas aperados para tres caballos. ${ }^{29}$

Detenerse en el detalle de las mercancías y las pertenencias que transportaban los mercachifles árabes puede contribuir a comprender sus condiciones materiales, más allá de los lugares comunes que han consolidado los relatos folklóricos y los memorialistas de la región. En este sentido, frecuentemente se hicieron referencias a que los vendedores ambulantes árabes vendían artículos sencillos y económicos, sin precisar el tipo de mercadería que comerciaban. Del inventario se desprende que Salomón comerciaba una importante variedad de productos de escaso valor, que en lo fundamental se limitaban a los rubros de tienda y mercería, aunque también vendía una serie de accesorios y adornos.

Como se menciona en el inventario, el expediente sobre el homicidio de José Salomón presenta la originalidad adicional de que el mercachifle tenía en su poder certificados de propiedad de caballos que había adquirido en distintas localidades y parajes del norte de la Patagonia. Debe recordarse que los vendedores ambulantes no podían solicitar marcas para sus animales en el caso de que no tuviesen una residencia fija. Pese a que los buhoneros solían contar con certificados de compra, la legislación específica impedía que se otorgasen boletos de marcas y señales a quienes no tenían una concesión de tierras. ${ }^{30}$ Es posible que esa medida tuviese el objetivo de favorecer la sedentarización o la radicación efectiva de la población.

Los certificados que José Salomón tenía en su poder habían sido firmados por los propietarios originales de los animales. Los actos administrativos para el traspaso de los derechos sobre los caballos generalmente se realizaban ante un juez de paz y dos testigos. Luego, las transferencias posteriores se consignaban sucesivamente en el mismo documento. En los certificados constaba que Salomón había adquirido 11 caballos, aunque solamente cuatro estaban en su poder al momento del homicidio. En la Tabla 1 se detallan las compras de los caballos y se precisa el número de animales vendidos, el comprador o compradores, los vendedores y el lugar de la venta.

Un número significativo de intercambios se había realizado entre Salomón y otros inmigrantes sirio-libaneses, como Felipe Curi, Fortunato Luís, Norah Sad y Elías Chaina. Este es un indicio de la alta movilidad que había en la propiedad de los animales al interior del colectivo inmigratorio árabe. En este sentido, los

29. "Adib A. Sede, homicidio", f. 3. Las transcripciones documentales son fieles a los originales en todos los casos.

30. Argeri 146. 
Tabla 1. Caballos adquiridos por José Salomón

\begin{tabular}{|c|c|c|c|}
\hline $\begin{array}{l}\text { Cantidad } \\
\text { de caballos }\end{array}$ & Comprador & Vendedor & Lugar de la venta \\
\hline 2 & José Salomón & Ángela Mena & Fita-Ruin \\
\hline 2 & $\begin{array}{l}\text { José Salomón } \\
\text { y Norah Sad }\end{array}$ & $\begin{array}{l}\text { Felipe Curi y } \\
\text { Fortunato Luis }\end{array}$ & Los Menucos \\
\hline 1 & José Salomón & Antonio Terbay & $\begin{array}{l}\text { Ilegible (venta original } \\
\text { Colonia Cervantes) }\end{array}$ \\
\hline 2 & José Salomón & Norah Sad & Los Menucos \\
\hline 1 & José Salomón & Vicente Paillalef & Casa de piedra (La Pampa) \\
\hline 1 & José Salomón & Javier Quintana & Huahuel Niyeo \\
\hline 1 & José Salomón & Elías Chaina & Anecón Grande \\
\hline 1 & José Salomón & Antonio Epullan & Huahuel Niyeo \\
\hline
\end{tabular}

sirio-libaneses frecuentemente mostraron su preferencia por hacer negocios entre connacionales.

Resulta llamativo que José Salomón había adquirido los animales en localidades y parajes muy distantes entre sí, e incluso había comprado uno de los caballos en el Territorio Nacional de La Pampa. Esto último puede ser indicativo de los extensos desplazamientos que realizaban los mercachifles árabes. En la Figura 1 se georreferenciaron las localidades y parajes registrados como los lugares en los que Salomón adquirió sus caballos. Si se conectan esos nodos, en el mapa se dibuja un arco que atraviesa el centro de Río Negro en sentido sudoeste, justamente donde Salomón compró la mayoría de los animales.

A continuación, se repasa un proceso policial contra un mercachifle árabe que permite establecer fuertes conexiones con el caso de Salomón. En este expediente también se consignaron detalladamente las mercaderías que transportaba el buhonero y se registraron indicios sobre sus estrategias de movilidad, aunque en este caso el procedimiento no se produjo por un hecho violento, sino a partir de los controles que ejercían las fuerzas policiales.

\section{Los mercachifles sirio-libaneses y el control policial}

El procedimiento policial que se llevó a cabo contra el vendedor ambulante árabe Jorge Fara por presunto comercio ilegal durante la década de 1920 en el norte de Chubut es un caso que puede contribuir a comprender la lógica itinerante de los mercachifles sirio-libaneses. Al mismo tiempo, puede ayudar a visibilizar las 
restricciones que buscaron imponer sobre este tipo de comercio algunas de las agencias estatales.

La investigación policial contra Fara se inició en abril de 1927, cuando el subcomisario de la localidad de Gan Gan, Eduardo Montero, le comunicó a la jefatura de policía en Rawson, capital del Territorio Nacional de Chubut, que había "sorprendido al vendedor ambulante Jorge Fara, en el rubro 'vinos, almacén y tabaco' sin patente" ${ }^{31}$ El subcomisario informó que empleados policiales que revistaban en su repartición habían interceptado al mercachifle árabe en Chacay, un paraje próximo a Gan Gan. Allí se procedió a constatar los permisos comerciales y se requisó la mercadería que el buhonero árabe transportaba en una "vagoneta". ${ }^{2}$ A continuación, los mismos policías inspeccionaron e hicieron recuento de otros productos que Fara había depositado previamente en la casa de Bartolomé Monsalve, un vecino de Chacay.

El subcomisario Montero dejó constancia de que se habían revisado las mercancías que transportaba Fara en presencia de dos testigos, José Ruíz y Juan de Dios Díaz, ambos albañiles chilenos que se encontraban circunstancialmente en el lugar, y con el consentimiento del mercachifle árabe. En el expediente se hizo una descripción pormenorizada de las mercaderías que fueron requisadas. De modo equivalente al caso de Salomón, el documento sobre las pertenencias de Fara es sumamente valioso si se considera que son escasos los inventarios de este tipo disponibles para la Patagonia septentrional.

La lista de mercancías que transportaba Fara en el interior de la vagoneta era la siguiente: "varios retazos de género, diez quesos, varios pañuelos de mano y de cuello, agujas, hilos, cinco o seis trajes hechos para hombre, dos kilos de tabaco y tres cajas de cigarrillos, dos planchas de vapor, dos frascos de agua florida y cuatro cajas de jabón 'Radium", ${ }^{33}$ De este primer inventario se desprende que las mercancías eran diversas y de poco valor, y la mayoría de ellas podían clasificarse dentro del rubro tienda y mercería. Luego de la requisa, el subcomisario Montero consideró que los dos kilogramos de tabaco y las cajas de cigarrillos constituían productos ilegales, y argumentó que la patente comercial de Fara no lo habilitaba para vender esos bienes. El mercachifle árabe adujo en su defensa que esas mercancías, como los 10 quesos, eran para su consumo personal.

En el segundo lote de productos, los que Fara había depositado en la casa de Monsalve, se encontraban "treinta bolsas de harina, tres bolsas de yerba, tres bolsas de azúcar, una vordalesa de vino, tres bolsas de maíz, seis bolsas chicas de arroz, una docena de escobas". ${ }^{34}$ Luego de la requisa, el subcomisario Montero acusó a Fara de comercio ilegal por la venta de bebidas alcohólicas sin patente, basándose en la

31. AHPC, Rawson, Fondo Gobernación del Chubut, exp. 3016, f. 1.

32. El término "vagoneta" hace referencia a pequeños carros de madera, generalmente impulsados por caballos, que se empleaban para el transporte de mercadería.

33. AHPC, Rawson, Fondo Gobernación del Chubut, exp. 3016, f. 8.

34. AHPC, Rawson, Fondo Gobernación del Chubut, exp. 3016, f. 9. 
existencia de la "barrica bordalesa". ${ }^{35}$ En este caso, el mercachifle alegó que esos productos no estaban destinados a la venta, sino que solo los había transportado desde la ciudad de Trelew por pedido especial de tres vecinos de la región. Fara precisó que había trasladado esas mercancías como un favor personal, y señaló a Rupertino Aguilar, Ismael Lagos y al maestro Enrique Della Croce como los dueños de las mercaderías. ${ }^{36}$

Luego de la primera etapa de instrucción policial, el subcomisario Montero resolvió suspender el permiso comercial de Fara y ordenó que el mercachifle árabe se presentara a declarar en la subcomisaría de Gan Gan, junto con los testigos José Ruíz, Juan de Dios Díaz y Bartolomé Monsalve. En su declaración, Fara se identificó como vendedor ambulante, de nacionalidad árabe, de 33 años de edad, con 16 años de residencia en Argentina, de estado civil casado y con poca instrucción. Fara adujo que en el momento en que fue interceptado por los empleados policiales, ejercía la actividad comercial "accidentalmente" en Chacay, y expuso además que contaba con la habilitación de una patente nacional para el rubro mercería y tienda. ${ }^{37}$ Finalmente, ratificó que no había vendido tabaco o vino. Por su parte, los vecinos Ruíz y Díaz declararon que conocían a Fara como mercachifle de la zona y se limitaron a avalar, en calidad de testigos, la lista de mercancías consignada en el informe policial.

Luego la investigación se demoró un par de meses porque Monsalve estuvo temporalmente imposibilitado para declarar, ya que se encontraba enfermo en la ciudad de Trelew. El proceso policial continuó el 3 de junio del mismo año con la declaración de Monsalve, quien expuso que Fara le había solicitado permiso para almacenar temporalmente mercaderías en su galpón y que en ese momento fue que se produjo el allanamiento policial. Monsalve declaró que le constaba: "que el nombrado [Fara] comerciaba como vendedor ambulante y esos artículos los vendería en tal carácter". ${ }^{38}$ El subcomisario Montero se basó en este testimonio para sostener su acusación de comercio ilegal contra Fara.

El mismo 3 de junio, Montero elevó las actuaciones a Arturo Sierra, jefe de la policía del Chubut, quien consultó al Departamento de Estadísticas sobre los antecedentes de Jorge Fara, una pesquisa que arrojó resultados negativos. Luego se elevó el expediente al gobernador Domingo Castro, máxima autoridad política

35. Se denomina "barrica bordalesa" al tonel de madera con capacidad para almacenar 225 litros de vino.

36. Enrique Della Croce se desempeñó como maestro rural en Chubut durante las primeras décadas del siglo XX, allí ocupó el cargo de director de la escuela No 63 de Chacay desde el año 1923. Luego, Della Croce fue director de la escuela N ${ }^{\circ} 95$ de Telsen, entre los años 1927 y 1936. Amílcar Amaya, "Un docente preocupado por los niños campesinos. Enrique Della Croce", Historias de vida de maestros chubutenses. Serie "Rescate" (Rawson: Centro de Docentes Jubilados del V.I.R.CH. Impres. Oficiales, 1995) 1-5.

37. Jorge Fara exhibió como aval comercial una patente nacional de la partida 397 que lo habilitaba a explotar los ramos de "Tienda, mercería y tejidos", para el período abril-diciembre de ese año.

38. AHPC, Rawson, Fondo Gobernación del Chubut, exp. 3016, f. 11. 
del territorio, quien el 28 de junio resolvió que eran injustificadas las medidas que había tomado el subcomisario Montero. El gobernador determinó que la cantidad de tabaco que trasportaba Fara era insuficiente como para constituir un delito; consideró, además, que los productos requisados en el domicilio de Monsalve no estaban necesariamente a la venta, ya que no se trataba de un almacén. Por último, llamó la atención sobre errores durante el procedimiento y destacó que Montero no le tomó declaración a los vecinos que Fara había señalado como propietarios de los productos.

El gobernador de Chubut determinó que el proceso policial había estado viciado de irregularidades y que el subcomisario Montero debía respetar la autorización de Fara para la venta ambulante de cualquier producto, con excepción de vinos, cervezas y tabaco. Para Castro, el subcomisario de Gan Gan había ocasionado perjuicios al mercachifle árabe por haber coartado su libertad de comercio, al retener indebidamente sus mercancías. Finalmente, ordenó que se devolviesen las mercaderías a Fara y sancionó a Montero con cinco días de suspensión, sin goce de sueldo.

Un mes más tarde, el 7 de julio, el subcomisario Montero elevó una solicitud de reconsideración. En su presentación reconocía que Fara llevaba poca cantidad de tabaco, no obstante, consideraba dudoso que el mismo fuese para consumo personal y "para un sólo día". ${ }^{39}$ Asimismo, argumentaba que, aun aceptando que la mercadería que Fara había depositado en casa de Monsalve era propiedad de vecinos de la región, el buhonero árabe debía ser sancionado porque no contaba con habilitación para comerciar como comisionista. Por último, Montero aclaraba que en ningún momento había retenido las mercaderías de Fara, y sostenía que se había limitado a labrar las actas administrativas. Finalmente, el 27 de julio, la gobernación denegó el pedido de reconsideración y le advirtió a Montero que sus justificaciones podían alumbrar nuevas faltas, además de que eventualmente podían corresponderle otras sanciones. La comunicación retornó desde la subcomisaría de Gan Gan el 28 de febrero de 1928. En ella, las nuevas autoridades de esa repartición informaban que Montero había dejado de ser empleado policial. Por otro expediente originado en la misma subcomisaría, se puede afirmar que, por lo menos desde septiembre de 1927, Montero había sido reemplazado por Mario Lauro. ${ }^{40}$

El proceso policial contra Fara ofrece distintos elementos para pensar las experiencias itinerantes de los mercachifles árabes en la Patagonia septentrional. En primer término, permite ratificar que los empleados policiales eran los encargados de controlar las actividades comerciales ambulantes y que, eventualmente, los mismos policías podían llegar a obstaculizar esos circuitos mercantiles. Al mismo tiempo, el expediente refleja los límites concretos de ese control social y registra la capacidad de defensa que tenían los buhoneros árabes. Además, el caso de Fara

39. AHPC, Rawson, Fondo Gobernación del Chubut, exp. 3016, f. 17.

40. El documento es la solicitud de patente comercial de Meljem García a la que se hizo referencia anteriormente. 
muestra que la alta movilidad de los vendedores ambulantes sirio-libaneses no implicaba necesariamente un desarraigo absoluto. Debe considerarse que Fara logró establecer relaciones sociales útiles para sus negocios pese a su condición itinerante, como lo evidencia el vínculo que tenía con Monsalve (el vecino que recibió parte de sus mercancías en depósito).

El resultado final del procedimiento es interesante porque parece contradecir el sentido común. Es decir, se podría presuponer que un subcomisario de una jurisdicción interior de la Patagonia no hubiera tenido problemas para inducir las resoluciones de las máximas autoridades del Territorio Nacional en su favor, más allá de las irregularidades administrativas del procedimiento. O que un mercachifle con condiciones materiales precarias y con escasas herramientas culturales, especialmente a causa de las dificultades que solían tener estos inmigrantes para comunicarse en español, tendría pocas posibilidades de hacer valer sus intereses. El resultado del conflicto también es llamativo porque refleja la función arbitral del gobernador y sus colaboradores más cercanos en la resolución de un conflicto policial menor. Un caso que podría haberse resuelto con una simple multa o la suspensión de un comerciante ambulante terminó dependiendo de la decisión final de la máxima autoridad del territorio.

No es posible determinar si los argumentos de Fara eran ciertos, no obstante, aunque hubiesen sido falsos, se puede considerar que fue una estrategia exitosa su decisión de circular con poca mercancía. En cuanto al subcomisario Montero, resulta dificil establecer si solamente buscaba evitar el comercio de productos sin la correspondiente patente. Por momentos en el expediente se insinúa que el subcomisario pudo estar interesado en decomisar las mercaderías o que buscaba restringir el comercio a pequeña escala para favorecer a los bolicheros establecidos en la región, aunque los elementos que ofrece la causa no son suficientes para ser concluyentes en ese sentido.

El caso de Fara sugiere tensiones o contradicciones entre los buhoneros árabes y las fuerzas policiales. Ese corolario es contrario a las conclusiones a las que arribaron otras investigaciones sobre la misma región, las cuales identificaron una complementariedad de intereses entre esos actores. Por ejemplo, Argeri señaló que en el sudoeste de Río Negro algunos mercachifles sirio-libaneses operaron como colaboradores de las fuerzas policiales y militares. ${ }^{41}$ Por otra parte, Ernesto Maggiori relevó testimonios sobre la significativa presencia de inmigrantes árabes entre los empleados policiales de Chubut, ${ }^{42}$ pese a las disposiciones ministeriales

41. Según Argeri, "fue notable la actividad de los grupos mercantiles sirio libaneses que, desde el recientemente fundado Fuerte Roca y al amparo del ejército — su principal cliente—, intentaron quebrar la preponderancia de las casas mercantiles de Carmen de Patagones. La estrategia se organizó a partir de la habilitación de una gran cantidad de mercachifles de la misma nacionalidad que se internaron en las tierras donde vivían los indios, vendiendo productos manufacturados y acopiando frutos del país - al mismo tiempo que hacían de informantes del ejército y la policía-". Argeri 182.

42. Ernesto Maggiori, Voces de un pasado todavía presente (Comodoro Rivadavia: Vela al Viento 
que buscaban evitar la incorporación de extranjeros en las fuerzas. ${ }^{43}$ Es posible que estos casos hayan convivido y que muestren distintas experiencias de los inmigrantes sirio-libaneses en relación con las autoridades policiales.

El procedimiento contra Fara refleja que la policía tenía una capacidad limitada para reprimir o interrumpir el comercio subalterno. Evidentemente, el escaso número de policías que revistaban funciones en la subcomisaría de Gan Gan no podía garantizar una regulación sobre los desplazamientos "nómades" o imponer la sedentarización. Finalmente, este caso muestra solapamientos y contradicciones entre instituciones y funcionarios públicos, si se considera la falta de coherencia entre las actuaciones de las autoridades locales y las resoluciones de las máximas autoridades territorianas. En este sentido, mercachifles árabes como Jorge Fara se mostraron exitosos para moverse entre las grietas de un poder estatal que se encontraba en pleno proceso de consolidación en la región.

\section{Conclusiones}

Los mercachifles árabes fueron actores arquetípicos del interior patagónico durante las primeras décadas del siglo $\mathrm{XX}$ y sus prácticas imprimieron una huella indeleble en el imaginario popular, aunque dejaron pocas marcas en los archivos públicos. Los inmigrantes sirio-libaneses convivieron con clasificaciones peyorativas sobre su oficio como buhoneros, lo que posiblemente generó que en sus memorias, y en las de sus descendientes, se borrara parcialmente esa etapa inicial de su ciclo migratorio. Ante las dificultades para construir un corpus documental que permitiera seguir satisfactoriamente las trayectorias de mercachifles árabes, se recurrió al entrecruzamiento de fuentes judiciales y policiales con documentación de tipología diversa.

Los expedientes policiales brindaron información sumamente original, como, por ejemplo, los inventarios sobre las mercancías que transportaban los buhoneros sirio-libaneses. Esas listas muestran que ellos vendían productos variados y de escaso valor, que mayormente correspondían a los rubros de tienda y mercería. Dichos inventarios posibilitan el cotejo de los registros históricos con los relatos folklóricos y con las memorias orales, al mismo tiempo que reflejan las pobres condiciones materiales de estos inmigrantes. Por otra parte, los certificados de compra de caballos que tenía en su poder José Salomón sugieren la amplitud te-

Ediciones Patagónicas, 2006) 56.

43. El semanario Golfo Nuevo informaba a fines de 1917 que el Ministerio del Interior recomendaba a los gobernadores de los Territorios Nacionales que: "las vacantes que se produzcan en el personal subalterno de las policías deben ser llenadas en los sucesivo con ciudadanos argentinos por considerarse oportuna y eficaz esta medida propagándose así el espíritu nacional en estas apartadas regiones y porque se ha notado que este elemento dura más tiempo en sus puestos, pues los extranjeros se mantienen en ellos mientras no hallan ocupaciones más lucrativas". Golfo Nuevo (Puerto Madryn) 24 de noviembre de 1917: 1. 
rritorial de las operaciones comerciales de los mercachifles árabes. Asimismo, esos documentos de compra muestran la alta movilidad de la propiedad de los animales entre los comerciantes sirio-libaneses y la fuerte cohesión de las redes de negocios al interior del grupo de connacionales. Esos registros - y el contexto del asesinato de Salomón - indican que los buhoneros árabes no eran actores aislados, sino que ellos estaban unidos por vínculos estrechos y compartían espacios comunes de sociabilidad, aunque operaran en espacios muy distantes entre sí.

Los mercachifles sirio-libaneses seguían itinerarios particulares que eventualmente podían ser interrumpidos por el control social que ejercían las fuerzas policiales, tal como sucedió en el caso de Jorge Fara. En contraste a lo propuesto en parte de los antecedentes, en este trabajo se pudieron identificar contradicciones y relaciones más complejas entre los buhoneros árabes y las fuerzas policiales. La alta movilidad y la fuerte dinámica de los itinerarios de los mercachifles sirio-libaneses desafiaron los intentos estatales por normalizar la circulación de bienes y personas en el interior patagónico. En este sentido, las trayectorias de los vendedores ambulantes árabes parecían ajustarse mejor a una lógica de espacio liso — según la propuesta de Deleuze y Guattari-, sin terminar de someterse a la disciplina social y al mantener vigentes formas de nomadismo que podían ser percibidas como una amenaza por parte de algunas agencias estatales.

Finalmente, casos como el de Fara exponen los límites del control policial y muestran las contradicciones que podían existir entre las autoridades locales y las territorianas. Los mercachifles sirio-libaneses pudieron defender sus intereses pese a su pobreza material y a las pocas herramientas culturales con las que contaban. Parte del éxito de los buhoneros árabes se puede explicar por su capacidad para moverse entre las grietas de un Estado que no era un actor monolítico y que estaba en pleno proceso de consolidación en la región.

\section{Fuentes}

\section{Manuscritas}

Archivo Histórico de la Provincia del Chubut, Rawson (AHPC)

Fondo Gobernación del Chubut

Archivo Histórico de la Provincia de Río Negro,Viedma (AHPRN)

Sección Justicia Letrada

Sección Inspecciones Generales de Tierras

\section{Impresas}

Amaya,Amílcar. "Un docente preocupado por los niños campesinos. Enrique Della Croce". Historias de vida de maestros chubutenses. Serie "Rescate". Rawson: Centro de Docentes Jubilados delV.I.R.CH. Impres. Oficiales, 1995. 
Casamiquela, Rodolfo. Relatos policiales patagónicos del Sargento Tello. Trelew: Fundación Ameghino, 2006.

Código rural para los territorios nacionales sancionado por el honorable Congreso Nacional el 14 de agosto de 1894. Buenos Aires: Imprenta y Encuadernación Latina, 1894.

\section{Periódicos y revistas}

Caras y Caretas (Buenos Aires) 1902.

Golfo Nuevo (Puerto Madryn) 1917.

\section{Bibliografía}

Archenti, Nélida. "Estudio de caso/s". Metodología de las ciencias sociales. Eds. Alberto Marradi, Nélida Archenti y Juan Ignacio Piovani. Buenos Aires: Emecé Editores, 2007.

Argeri, María Elba. De guerreros a delincuentes. La desarticulación de las jefaturas indígenas y el poder judicial. Norpatagonia, 1880-1930. Madrid: Consejo Superior de Investigaciones Científicas, 2005.

Bandieri, Susana. Historia de la Patagonia. Buenos Aires: Sudamericana, 2005.

Chávez, Matías. "Cartografias árabes. Trayectorias, territorialidad y redes sociales de inmigrantes sirio-libaneses en la Patagonia septentrional (1900-1955)". Tesis de doctorado en Historia, Universidad Nacional del Centro de la Provincia de Buenos Aires, 2019.

Comerci, María Eugenia. "Relaciones de intercambio en el oeste pampeano: el papel de los ambulantes”. Estudios Socioterritoriales. Revista de Geografía 18 (2015): 13-29.

Conti, Santiago. "Mercachifle. (Región Patagonia, Argentina, 1900-2019)". Diccionario del agro iberoamericano. Eds. Alejandra Salomón y José Muzlera. Buenos Aires: TeseoPress, 2020.

Deleuze, Gilles y Félix Guattari. Mil Mesetas. Capitalismo y esquizofrenia.Valencia: PreTextos, 1988.

Iuorno, Graciela, Glenda Miralles y Karim Nasser. “Actores y espacio público en la etapa territorial rionegrina. El Departamento General Roca y su integración desigual". Horizontes en perspectiva. Contribuciones para la Historia de Río Negro 1884-1955. Coords. Martha Ruffini y Ricardo Freddy Masera.Viedma: Fundación Ameghino, 2007.

Madariaga, Marta. "El trueque en los sistemas agrarios campesinos". Crianceros y chacareros en la Patagonia. Coords. Mónica Bendini y Carlos Alemany. Neuquén: Editorial La Colmena, 2004.

Maggiori, Ernesto. Voces de un pasado todavía presente. Comodoro Rivadavia:Vela alViento Ediciones Patagónicas, 2006.

Pérez, Liliana E. Tels'en. Una historia social de la meseta norte del Chubut. Patagonia 18901940. Rawson: Secretaría de Cultura de Chubut, 2012.

Radovich, Juan Carlos y Alejandro Omar Balazote. "Mercachifles y cooperativas: un 
análisis del intercambio". Runa. Archivo para las Ciencias del Hombre 19 (19891990): 135-146.

Ramos, Ana Margarita. "Trayectorias de aboriginalidad en las comunidades mapuche del Noroeste de Chubut (1990-2003)". Tesis de doctorado en Antropología, Universidad de Buenos Aires, 2005.

Troncoso, Ana María. Todavía no: el proyecto civilizador entre las prácticas sociales y las estrategias de resistencia, de negociación y de apropiación en la meseta norte chubutense (1900-1970). Trelew: [s.e.], 2015. 